\title{
Secondary metabolites of the leaf surface affected by sulphur fertilisation and perceived by the cabbage root fly
}

\author{
Cristina Marazzi, Bruno Patrian and Erich Städler
}

Eidg. Forschungsanstalt, Postfach 185, CH-8820 Wädenswil, Switzerland

\begin{abstract}
Summary. Surrogate leaves treated with methanolic leaf surface extracts of Brassica napus L. (cv Express) plants that received three different sulphur fertilisation treatments showed even more marked differences by the oviposition choice of Delia radicum L. than the potted plants. This confirms that the oviposition preference of D. radicum is mediated by chemical compounds on the leaf surface and that the quality of host-plants in terms of their nutrition status can be perceived by the female insect.

The oviposition data were positively correlated with the content of fractionated surface extracts containing either CIF ("cabbage identification factor"; 1,2-dehydro-3-thia4,10,10b-triaza-cyclopenta[.a.]fluorine-1-carboxylic acid) or glucosinolates. Electrophysiological recordings from the tarsal chemoreceptor sensilla $\mathrm{C}_{5}$ and $\mathrm{D}_{3,4}$ showed that receptor neurons react to glucosinolate- and CIF-fractions. We found that the chemosensory activity of specific glucosinolate- and CIF-receptor neurons corresponded with the respective behavioural activity in the oviposition choice assays. The responses of $D$. radicum to glucosinolates in the electrophysiological recordings studies corresponded to the observed oviposition preference on plants or artificial leaves characterised with an higher amount of glucosinolates on leave surfaces. The presented data suggested that CIF and glucosinolates are involved in host-plant preference of $D$. radicum and are perceived by tarsal chemoreceptors.
\end{abstract}

Key words. Sulphur plant nutritions - Brassica napus Delia radicum - Anthomyiidae - Diptera - oviposition choice - contact chemoreception - glucosinolates - CIF

\section{Introduction}

We recently showed (Marazzi and Städler, in preparation) that sulphur (S) fertilisation of oilseed rape, Brassica napus (L.), influences host-plant preference in the cabbage root fly, Delia radicum (L.). The question arises as to which plant characters are perceived by the females leading to the observed preference. The physical and chemical stimuli that influence the oviposition behaviour of the cabbage root fly have been extensively investigated by different authors

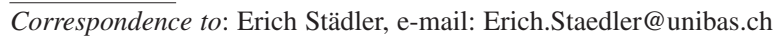

(reviewed in Städler 2002). D. radicum oviposition site selection is influenced by the volatile hydrolysis products of GSLs (Wallbank \& Wheatley 1979; Ellis et al. 1980; Nottingham \& Coaker 1985; Tuttle et al. 1988), and plant odour plays an additional role in host selection also after landing (De Jong \& Städler 1999). The role of other factors, including non-volatile chemicals on the leaf surface (Roessingh et al. 1992b; Hurter et al. 1999; De Jong et al. 2000) as well as leaf colour (Prokopy \& Roitberg 2001) have been investigated. Furthermore, certain physical characteristics, including a waxy surface, a stem, and vertical folds, increase oviposition of $D$. radicum on surrogate plants (Roessingh \& Städler 1990). Roessingh et al. (1992a) reported that purified glucosinolates (GSLs) stimulate $D$. radicum to oviposit, but they concluded that these compounds account only partially for the stimulatory activity of the plant surface. Roessingh et al. (1992a), and more recently Hurter et al. (1999) and De Jong et al. (2000) were able to isolate and identify the so-called CIF compounds ("cabbage identification factor"; 1,2-dehydro-3-thia4,10,10b-triaza-cyclopenta[.a.]fluorine-1-carboxylic acid and derivates) from the leaf surface of Brassica oleracea, one of the major cultivated host plants that induce oviposition in the cabbage root fly, Delia radicum (L.). Baur et al. (1996) found that the content of CIF in four different genotypes of two Brassica species (B. rapa L., B. oleracea L. var. acephala D.C. ) is also related to the oviposition preference of the cabbage root fly. D. radicum. Contact chemoreceptor neurons in the $\mathrm{D}_{3,4}$ sensilla chaetica (D-hairs) on the ventral side of the tarsi have been found to be sensitive to GSLs (Roessingh et al. 1992a). In addition, Roessingh et al. (1997) reported that the pair of ventro-medial C-sensilla on the fifth tarsomer contain two receptors neurons sensitive either to GSLs or CIF.

More recently, also Städler et al. (2002) illustrated oviposition preference in different host-plant species of the family Brassicaceae using plant compounds on the leaf surface. But only limited data are available on the role of environmental variation such as plant nutrition, in particular of sulphur (S), on the aforementioned relationship.

The influence of S plant nutrition on the behaviour of the insects has been studied before by Wolfson (1980) on Pieris rapae (L.), Koritsas and Garsed (1985) and Yusuf and Collins (1998) on Brevicoryne brassicae (L.). However, the choice and performance of insects could not always be 
attributed to the plant fertilisation, because GSLs levels are also influenced by genetical or environmental factors (Bodnaryk 1997; Hopkins et al. 1998). In this context, Dosdall et al. (2002) reported that $\mathrm{S}$ application rate on $B$. rapa has a significant effect on $D$. radicum egg deposition and root damage in the field, but this effect varied depending on the year and the site, indicating that environmental factors are of great importance in determining infestation levels by this pest, and the oxidation state of $S$ in soil. In agreement with these findings, Kim et al. (2002) provided evidence that $S$ and nitrogen applications strongly affected GSL content in the edible parts of B. rapa plants.

We investigated the effect of $S$ plant nutrition on the oviposition behaviour and sensory perception of the cabbage root fly. Brassica napus plants were chosen because of their high sensitivity to S (Scherer 2001) and their economic importance. We compared GSLs and CIF production, by means of leaf surface extracts, in plants grown under three different levels of S supply and assessed the role of these compounds on $D$. radicum behavioural and chemosensory responses.

\section{Materials and methods}

\section{Insects}

All the Delia radicum (Diptera, Anthomyiidae) flies originated from our continuous laboratory culture (restarted with field-collected maggots in 1996) reared according to the method of Finch and Coaker (1969). Approximately 100 adult flies were housed in cubic screen cages $(65 \times 65 \times 65 \mathrm{~cm})$ and held in a climate-controlled room $\left(21 \pm 1{ }^{\circ} \mathrm{C}, 80 \% \mathrm{RH}\right.$ and $16 \mathrm{~h}$ photophase). The cages were provided with a mixture of raw cane sugar, yeast hydrolysate and water (4:1:1) applied on absorbent tissue strips, supplying the flies' food. Water and $10 \%$ sugar solution soaked into cotton-wool were offered separately. Intact cabbage plants (B. napus cv CC-Cross F1) at the pre-bolt stage, with a thin layer of fine grain-sized $(\varnothing 3-5 \mathrm{~mm})$ sand on the top of the soil surface were used as oviposition sites. The eggs were collected by flotation in water and transferred to swede roots or kohlrabi planted in moist sand at $20 \pm 1{ }^{\circ} \mathrm{C}, 90 \%$ $\mathrm{RH}$ and $16 \mathrm{~h}$ photophase.

\section{Plants}

The oilseed rape (B. napus cv. Express) plants were grown under controlled conditions (glasshouse: $\left.22 \pm 3^{\circ} \mathrm{C}, 16: 8 \mathrm{~L}: \mathrm{D}\right)$. The seeds were arranged individually in plastic pots $(\varnothing 9 \mathrm{~cm})$ containing fine quartz sand (granules of $1.5 \times 2.2 \mathrm{~mm}$ ) covered with a surface layer of thicker granules $(3.0 \times 5.6 \mathrm{~mm})$ to improve gaseous exchanges. The plants were watered twice a week using a modified "Hoagland" nutrient solution to provide the three different $S$ levels of fertilisation: $\mathrm{S}_{\mathrm{n}}=1 \mathrm{mM}$ of $\mathrm{MgSO}_{4}$ (normal S concentration in a Swiss field, confirmed by D. Ryser, personal communication); $\mathrm{S}_{+}=2 \mathrm{mM}$ of $\mathrm{MgSO}_{4}$ (high sulphur level) and $\mathrm{S}_{0}$ ( $\mathrm{S}$-free level), which was obtained by replacing $\mathrm{MgSO}_{4}$ with $\mathrm{MgCl}_{2}(1 \mathrm{mM})$. With the exception of sulphur and chloride, all other macro- and micronutrients were kept constant, according to the original recipe (Lemma Media, see Table 1) (Beaumont et al. 1976).

\section{Oviposition choice assays}

Bioassay with artificial leaves: We used the same surrogate leaves treated with leaf-surface extracts of the selected plants as
Table 1 Nutrient additions for each treatment (mM, 1M)

\begin{tabular}{lccc}
\hline & & \multicolumn{2}{c}{ Element (source) } \\
\cline { 3 - 4 } Treatment & Abbreviation & $\begin{array}{c}\text { Sulphur } \\
\left(\mathrm{MgSO}_{4}\right)\end{array}$ & $\begin{array}{c}\text { Chloride } \\
\left(\mathrm{MgCl}_{2}\right)\end{array}$ \\
\hline Sulphur-free regime & $\mathrm{S}_{0}$ & 0 & 1.0 \\
Normal sulphur regime & $\mathrm{S}_{\mathrm{n}}$ & 1.0 & 0 \\
Sulphur-rich regime & $\mathrm{S}_{+}$ & 2.0 & 0 \\
\hline
\end{tabular}

previously described by Roessingh et al. (1992a). Oviposition bioassays were conducted in the same cages as those described for the rearing, containing approximately 100 adult moths. As for the bioassay with real plants, 4 surrogate leaves ( 2 for each treatment: $S_{n}$ (control) vs $S_{0}$ or $S_{n}$ (control) vs $S_{+}$), were arranged in a circle on the floor of the cage.

We replicated each pair-wise assay 20 times and after each count new surrogate leaves were used and the positions were changed clockwise to minimize any influence exerted by uneven light distribution. After an oviposition period of 24 hours, the eggs laid on each artificial leaf were counted and expressed as a percentage of the total number of eggs laid on all artificial leaves within one bioassay period. Thus, the resulting preference percentages for the compared treatments $\left(S_{n}\right.$ vs $S_{0}$ and $S_{n}$ vs $S_{+}$respectively) totalled $100 \%$. A Mann-Whitney U-test was performed on the percentages to determine the significant differences between treatments.

\section{Chemical extraction and analysis}

Leaf-surface chemicals were extracted using the same extraction procedure described by Städler and Roessingh (1991) to obtain methanolic leaf-surface extracts from $\mathrm{S}_{0}, \mathrm{~S}_{\mathrm{n}}$ and $\mathrm{S}_{+}$plants at the 3-4 true leaf stage. Amounts and concentrations of samples were expressed in gle (gram leaf equivalent) or gle/ml, respectively. One gle represents the amount of leaf-surface extract obtained by dipping in a solvent $1 \mathrm{~g}$ of fresh leaf material. For the oviposition assays, these extracts were applied on the surrogate leaves. The GSL fractions of the extracts were separated from the fractions containing CIF (De Jong et al., 2000) compounds using cation exchange resins (described by Baur et al., 1996).

In addition to the surface extract, a total leaf extract (homogenate) of each treatment was prepared and its glucosinolate content analysed qualitatively and quantitatively (Marazzi et al., in preparation). We used the same extraction procedure described by Griffiths et al. (2001) to obtain desulfoglucosinolates. Although plant handling was particularly cautious, unwanted GSL leakage due to plant's damaging cannot be excluded but it would certainly be randomly distributed between the treatments. The glucosinolates, twenty $\mu 1$ aliquots (representing approximately 2 leaves), were analysed by HPLC. The analytical column used was equipped with a Lichrospher $(100 \mathrm{RP} 18,5 \mu \mathrm{m}, 4 \times 250 \mathrm{~mm})$. The binary mobile phase system was composed of distilled water (A) and water : acetonitrile, $80: 20$ (B). The analysis was run with the following gradient program: 0 to 45 min linear gradient 0 to $100 \% \mathrm{~B}$ and then held for $5 \mathrm{~min}$ on $100 \% \mathrm{~B}$. The flow rate was $1 \mathrm{ml} / \mathrm{min}$ and the detection of desulfoglucosinolates was monitored with an UV/VIS detector at $230 \mathrm{~nm}$.

Quantifications were based on 2 GSL standard solutions (Doon Major and Dwarf), prepared and quantified at the SCRI in Dundee, Scotland. The Jasco HPLC system was equipped with Chromeleon software, which was used for data acquisition and analyses. These analytical data are used in the present paper for the correlation between oviposition and sensory data. Pure CIF-1 was isolated from B. napus var. napobrassica by De Jong et al. (2000). 


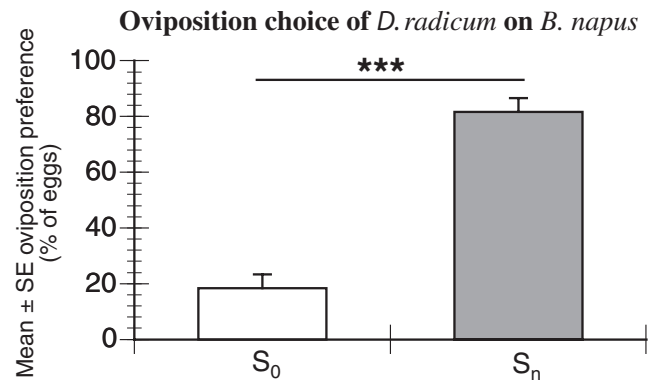

Oviposition choice of $D$. radicum on artificial leaves

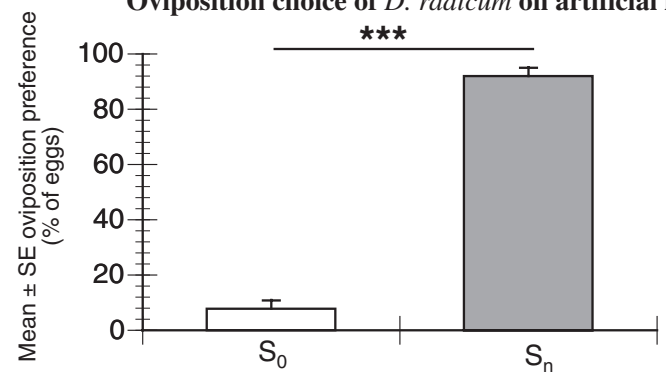

Glucosinolates content of $B$. napus plants

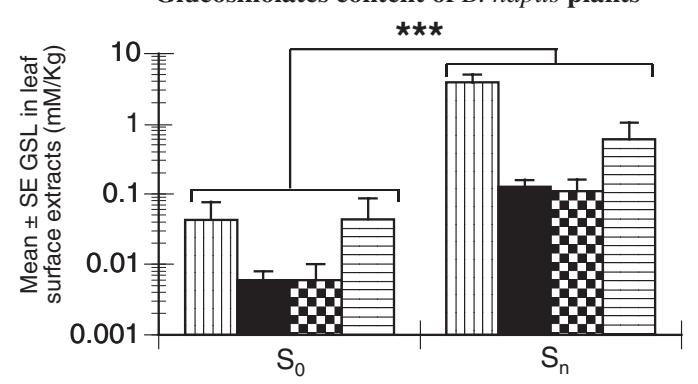

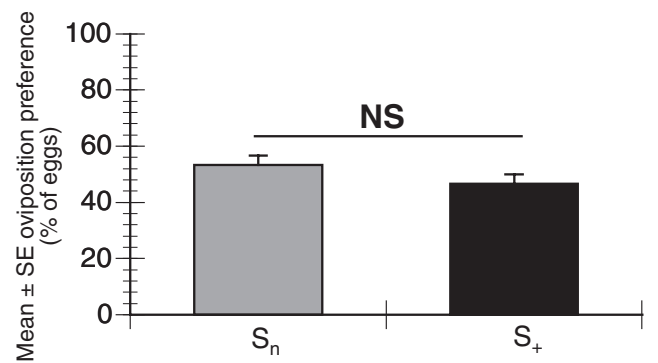

A

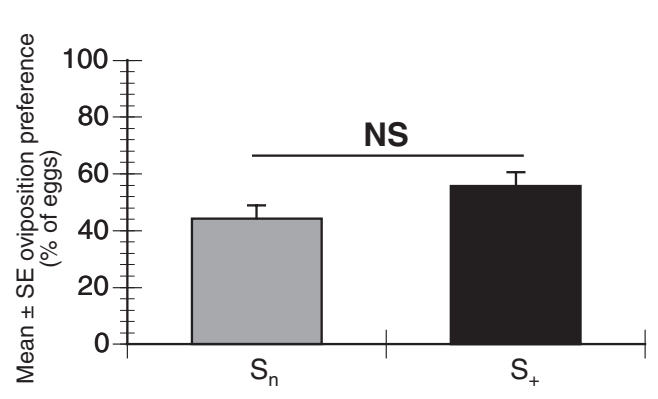

B

Fig. 1 Oviposition choice of D.radicum affected by sulphur fertilisation. (A) Proportions of eggs laid on $S_{0}$ (sulphur free), $S_{n}$ (normal sulphur supply) and $\mathrm{S}_{+}$(sulphur-rich) B. napus plants. These data are the same as reported in Marazzi et al. (in preparation) and are shown for comparison. Number of replicates: 20. (B) Proportions of eggs laid on artificial leaves sprayed with extracts of $\mathrm{S}_{0}, \mathrm{~S}_{\mathrm{n}}$ and $\mathrm{S}_{+} B$. napus at 1 gle. Number of replicates: 20. (C) GSL content of $S_{0}, S_{n}$ and $S_{+}$B. napus plant extracts (10 g freeze-dried plant material). These data are the same as reported in Marazzi et al. (in preparation) and are shown for comparison. Number of replicates: 5

\section{Electrophysiology}

We recorded the activity of receptor neurons of the ventro-medial $\mathrm{C}$-sensillum on the fifth tarsomer $\left(\mathrm{C}_{5}\right)$ and the ventro-lateral D-sensilla on the third and fourth tarsomer $\left(D_{3,4}\right)$ of 1 day-old female flies using the same technique and set up as described by De Jong et al. (2000). All the nerve impulses (spikes) recorded were counted in the time interval of 50-1050 ms after contact of the recording electrode with the tip of the sensillum using our spike train analysis software (STA). The spike counts were averaged for the $\mathrm{D}$ and $\mathrm{C}$ sensilla. We investigated a total of $25 \mathrm{C}_{5}$ - and $24 \mathrm{D}_{34^{-}}$ sensilla. The preparations that gave less than 40 spikes with the standard $10 \mathrm{ng} / \mathrm{ml} \mathrm{CIF-1}$ or more than 20 spikes with $\mathrm{KCl} 10 \mathrm{mM}$ in the initial test recordings from the $\mathrm{C}_{5}$ - sensillum were excluded. The $\mathrm{S}_{0}, \mathrm{~S}_{\mathrm{n}}$ and $\mathrm{S}_{+}$plant extracts (GSL and CIF fractions) were examined each at 0.1 and 1 gle. The set of stimuli was tested sequentially on the sensilla in the following order: $S_{0}, S_{n}$ and $S_{+}$, always starting with the lowest plant extract concentration. Significant differences between responses to the plant extracts were detected with the Friedman test. Comparisons among selected treatments were then performed using a Wilcoxon Signed Rank Test.

\section{Results}

\section{Oviposition choice assays}

Bioassay with artificial leaves: The choice assays with surrogate leaves sprayed with methanolic leaf surface extracts yielded the same ranking of preference described by Marazzi et al. (in preparation) and shown here for comparison (Fig. 1A). The surrogate leaves proved to be even more active in the oviposition choice of D. radicum (Fig. 1B). The number of eggs laid was significantly higher (MannWhitney, $\mathrm{n}=40, \mathrm{p}<0.001$ ) on artificial leaves spayed with $S_{n}$ plant extracts than on artificial leaves sprayed with $S_{0}$ plant extract, representing an approximately 10-fold increase. As with real plants, no significant difference was found between the number of eggs laid on artificial leaves sprayed with $\mathrm{S}_{\mathrm{n}}$ and $\mathrm{S}_{+}$plant extracts (Mann-Whitney, $\mathrm{n}=40, \mathrm{p}<0.3302$ ). 


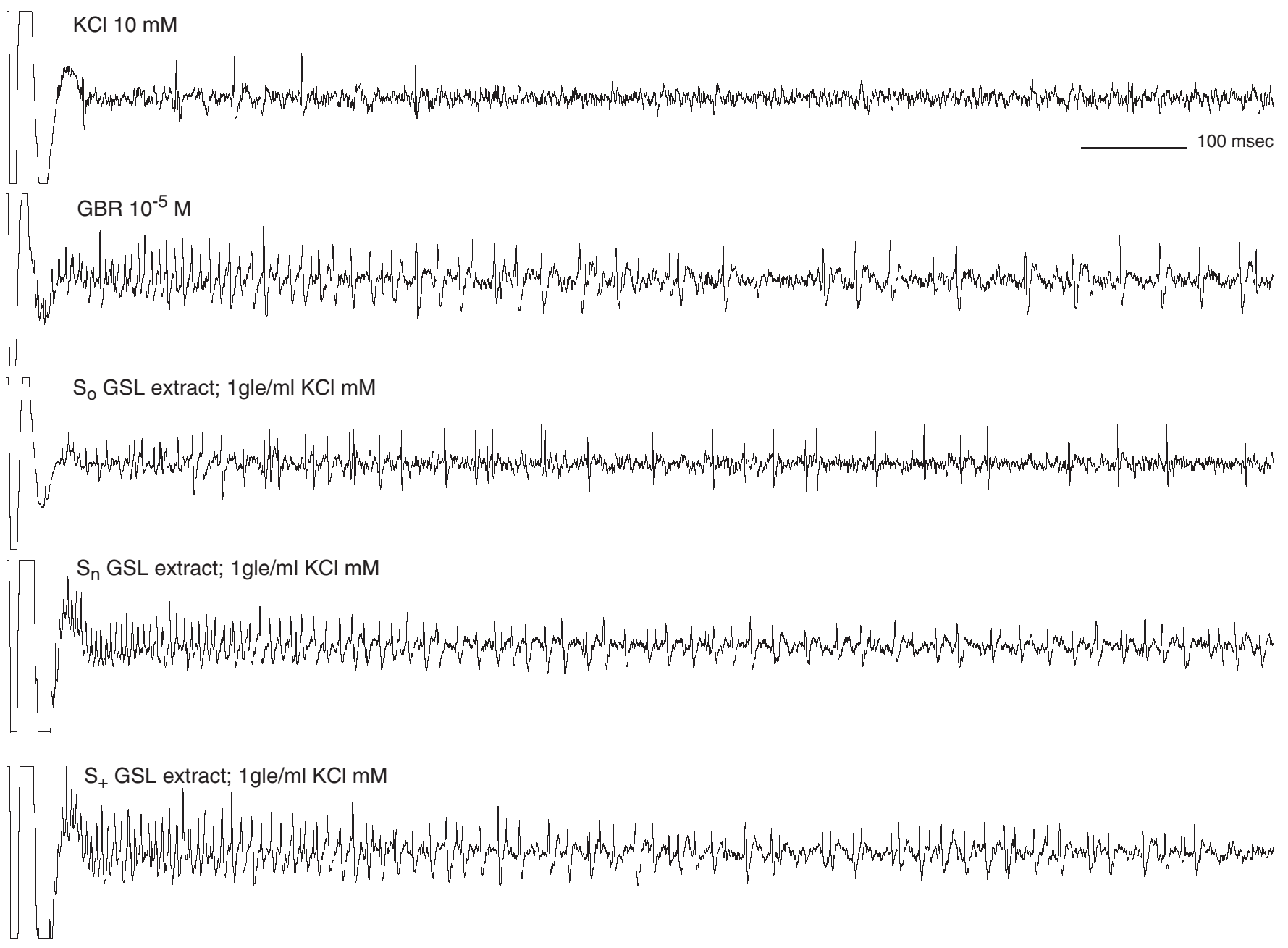

Fig. 2 Electrophysiological recordings from a $\mathrm{D}_{3}$ sensillum stimulated with GSL fractions of $\mathrm{S}_{0}, \mathrm{~S}_{\mathrm{n}}$ and $\mathrm{S}_{+}$B. napus plant extracts. Standard: glucobrassicin (GBR) $10^{-5} \mathrm{M}$, solvent: $\mathrm{KCl} 10 \mathrm{mM}$. gle $/ \mathrm{ml}=$ gram leaf equivalent per ml. $\mathrm{S}_{0}=$ sulphur free, $\mathrm{S}_{\mathrm{n}}=$ normal sulphur and $S_{+}=$sulphur-rich plant extracts

\section{Chemical analysis of B. napus plant extracts}

The presence of eight GSLs was consistently detected in all tissue from the three populations of $B$. napus tested (Fig. 1C). These data are the same as presented by Marazzi et al. (in preparation) in connection with the study of Plutella xylostella. Briefly, Fig. 1C shows the differences in the GSL content of the three entries of B. napus plants, and reflects female oviposition preference, where the plant extracts that were favoured most, yielding the higher number of eggs per female, were those containing the higher GSLs proportion.

\section{Sensory data}

GSL-fractions: The examples of recordings from a $D_{3}$ sensilum show that the stimulation of individual $\mathrm{D}_{3}$ or $\mathrm{D}_{4}$ sensillum with the three samples of GSL-fractions evoked responses that were different also qualitatively (Fig. 2). Compared to $\mathrm{S}_{0}$ extracts, we observed an increase in the number of large-sized spikes in response to $S_{n}$ or $S_{+}$GSL-fractions.

The GSL-sensitive neurons of all the $\mathrm{D}_{3}$ - and $\mathrm{D}_{4}$-sensilla investigated responded with increased spike frequencies to the GSL fractions $(1 \mathrm{gle} / \mathrm{ml})$ in a $\mathrm{S}$ concentration-dependent manner (Fig. 3). The comparisons between the different fractions both at $0.1 \mathrm{gle} / \mathrm{ml}$ and $1 \mathrm{gle} / \mathrm{ml}$ revealed that the $S_{n}$ and the $\mathrm{S}_{+}$GSL-fractions stimulated more spikes than the $\mathrm{S}_{0}$ GSL fraction (Wilcoxon Signed Rank Test, $n=24, p=0.0397$ respectively $\mathrm{p}=0.0013$, Fig. 3). No significant difference was detected between spike counts of $S_{n}$ and $S_{+}$GSL fractions (Wilcoxon, $\mathrm{n}=24, \mathrm{p}=0.0865$, Fig. 3).

The stimulation of C-hairs with GSL-fractions evoked on average less than $40 \mathrm{spikes} / \mathrm{sec}$ and the results are shown in Fig. 4. Clearly the GSL sensitive neuron was responding too, although the difference between $\mathrm{S}_{0}$ and $\mathrm{S}_{\mathrm{n}}$ or $\mathrm{S}_{+}$was not so clear as in the D-sensilla (Fig. 5). The chemosensory responses at both concentration $0.1 \mathrm{gle} / \mathrm{ml}$ and $1 \mathrm{gle} / \mathrm{ml}$ showed a significant difference between $\mathrm{S}_{0}$ and $\mathrm{S}_{\mathrm{n}}$ GSL-fractions (Wilcoxon, $\mathrm{n}=23, \mathrm{p}=0.0337$ ) and between $\mathrm{S}_{0}$ and $\mathrm{S}_{+} \mathrm{GSL}-$ fractions (Wilcoxon, $\mathrm{n}=24, \mathrm{p}=0.0133$ ). Conversely, no significant difference was found between responses to $S_{n}$ and $\mathrm{S}_{+}$GSL fractions (Wilcoxon, $\mathrm{n}=25, \mathrm{p}=0.2194$, Fig. 5).

CIF-fractions: Fig. 6 shows representative recordings from one $\mathrm{C}_{5}$-sensillum. Stimulation with $\mathrm{KCl} 10 \mathrm{mM}$ (solvent control) caused very little activity compared to pure CIF, which 
already at $10 \mathrm{ng} / \mathrm{ml}$ induced more than 70 spikes $/ \mathrm{sec}$ in the $\mathrm{C}_{5}$-sensilla. Recordings with the $\mathrm{S}_{0}$ CIF-fraction evoked fewer, and more irregular spike patterns than $\operatorname{did} S_{n}$ and $S_{+}$ CIF-fractions.

The chemosensory activity of this neuron in the $\mathrm{C}_{5}$ sensilla in response to the CIF-fractions (Fig. 7) corresponded well with the behavioural activity. The CIF-fractions of $S_{n}$ and $S_{+}$plant extracts were neurophysiologically more effective than the CIF-fraction of $S_{0}$ plant extracts. The observed activity can most likely be attributed to the CIF content, since the chemical analysis of these extracts revealed that no GSLs were present (detection threshold: $1 \mu \mathrm{g} \mathrm{GSL} / \mathrm{ml}$ crude extract for alkenes, hydroxyalkenes, thioalkenes and benzylGSL and $0.3 \mu \mathrm{g}$ GSL/ml crude extract for indolyl-GSL). The comparison among the chemosensory responses at both concentration $0.1 \mathrm{gle} / \mathrm{ml}$ and $1 \mathrm{gle} / \mathrm{ml}$ showed a significant difference between $S_{0}$ and $S_{n}$ CIF-fractions (Wilcoxon, $n=25$, $\mathrm{p}=0.0370$ ) and between $\mathrm{S}_{0}$ and $\mathrm{S}_{+}$CIF-fractions (Wilcoxon, $\mathrm{n}=25, \mathrm{p}=0.0323$ ). Conversely, no significant difference was found between responses to $S_{n}$ and $S_{+}$CIF fractions (Wilcoxon, $n=25, p=0.9571$, Fig. 7).

\section{Correlations between behaviour and GSL analysis}

The results of the behavioural assay (Figs. 1A, 1B) correlated directly with the GSLs content of the plants, which was severely affected by the lack of $S$ in the plant nutrition (Fig. 1C). The significant differences in female chemoreception noted during the electrophysiological recordings were reflected in the results of the GSL content of plant extracts used for the tarsal stimulation.

\section{Discussion}

Our study is one of the first to show that S supply clearly affect insect behaviour and sensory physiology. So far only the effects of nitrogen fertilisation in Brassica oleracea crops have been shown to stimulate insect population as a result of increased consumption and higher utilisation rate (Jansson et al. 1991). In contrast, the influence of $\mathrm{S}$ nutrition on the responses of the plant to pest attacks has received little attention, and it is mainly the balance between nitrogen and $\mathrm{S}$ that is documented (Wolfson 1982), often in relationship with sucking insects (Koritsas and Garsed 1985). However, these studies did not relate lower insect preference and performance to nutrient-deficient plants. Even Dosdall et al. (2002), who specifically studied the responses of $D$. radicum to changes in S plant treatment in the field, concluded that only minor benefit may be derived from the use of S applications as a root maggot control strategy. In the present study, by utilising an extreme range in S supply to the plant, we have successfully revealed clear differences in the behaviour of the insects affected, confirming also the conclusion of Dosdall et al. (2002) and Kim et al. (2002) as well.

Oviposition choice assays with real plants and artificial leaves

An increased S supply to the plants correlated with an increase in oviposition by the adults. The lack of sulphur in the plant nutrient solution reduced oviposition on both true

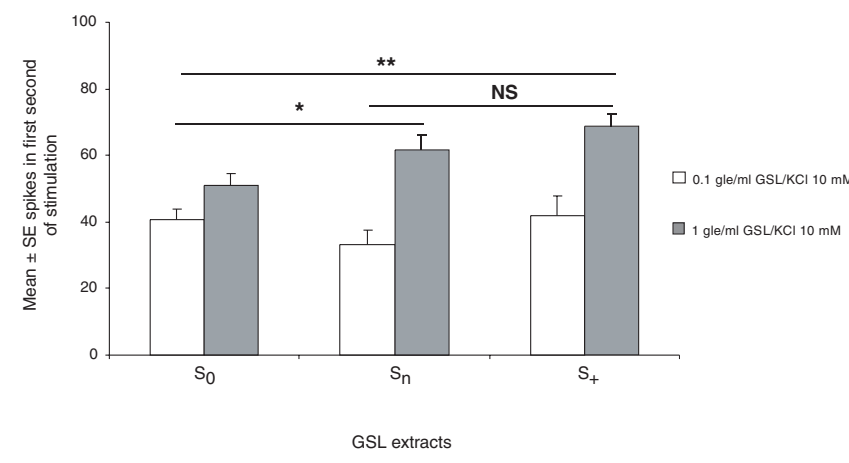

Fig. $3 \mathrm{D}_{3,4}$ tarsal sensilla of $D$. radicum stimulated by GSL fractions of different $B$. napus varying in $S$ nutrition. Numbers of analysed recordings: $S_{0}-S_{n}: 15 ; S_{0}-S_{+}: 19 ; S_{n}-S_{+}: 18 . S_{0}=$ sulphur free, $S_{n}=$ normal sulphur and $S_{+}=$sulphur-rich plant extracts

plants and artificial leaves. Surrogate leaves treated with methanol plant extracts showed a more pronounced preference than real plants (Figs. 1A, 1B) suggesting that the oviposition choice largely depends on chemical substances on the leaf surface that are methanol extractable and polar. In contrast, the morphological changes, such as leaf colour or plant size, were not crucial factors in the female choice, as the plants and artificial leaves used for the assays were very similar in appearance.

\section{Chemical analysis of B. napus plant extracts}

Since $D$. radicum reacts to pure GSL (Roessingh et al. 1992a), we expected that the acceptability of B. napus by $D$. radicum would be correlated by the GSL levels of the plant. So far, however, in other studies, no evidence of a correlation between the GSL content of the plants and insect preference was reported. For instance, Nair et al. (1976) found that the total GSL concentration in the leaves of six cruciferous plant species did not correlate with the oviposition response of $D$. radicum. The authors explained this lack of correlation by the presence or absence of plant inhibitors. But, among the different crucifers tested by Städler et al. (2002) and Griffiths et al. (2001), the authors found a clear correlation. However, it should be noted that this was only true for benzyl and indolyl GSLs, and not for aliphatic GSLs. We found that the amount of GSLs and CIF in the leaf surface determine oviposition preference in $D$. radicum, confirming the conclusions of Ellis et al. (1980), who showed a relationship between the amount of volatile GSLs hydrolysis products in radish extracts and the oviposition choice of the cabbage root fly. They found that radish varieties with an increased content of 4-methylthio-3butenylisothiocyanate and 1-cyano-4 methylthio-3-butene stimulated more the oviposition.

Since volatiles can have a significant synergistic effect on oviposition (De Jong \& Städler 1999), they may also be part of the stimulating effect of our extracts. However, we believe that isothiocyanates played a minor role, because our extraction procedure avoided the myrosinase enzyme reaction. A chemical analysis of the leaves clearly showed that $\mathrm{S}$ deficiency depressed the biosynthesis of GSLs and $\mathrm{CIF}$, which reduces oviposition stimulation. 


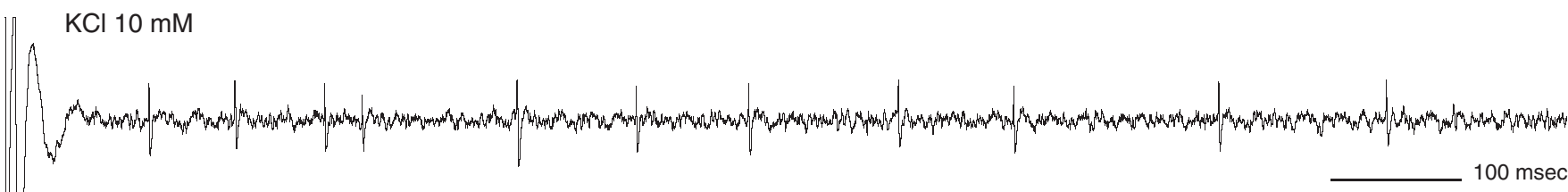

$$
\text { GBR } 10^{-5} \mathrm{M}
$$

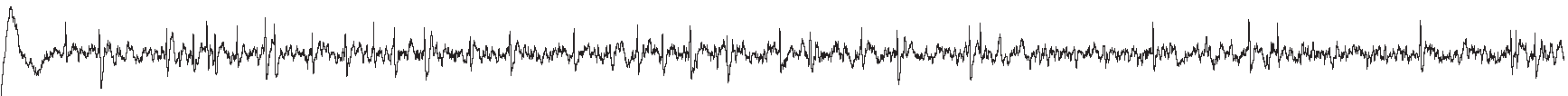

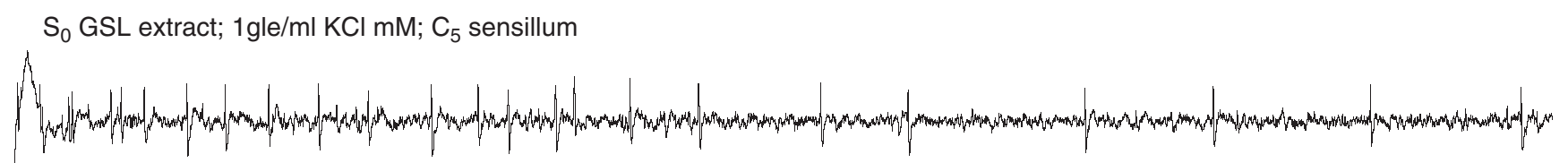

$\mathrm{S}_{\mathrm{n}}$ GSL extract; $1 \mathrm{gle} / \mathrm{ml} \mathrm{KCl} \mathrm{mM;} \mathrm{C}_{5}$ sensillum

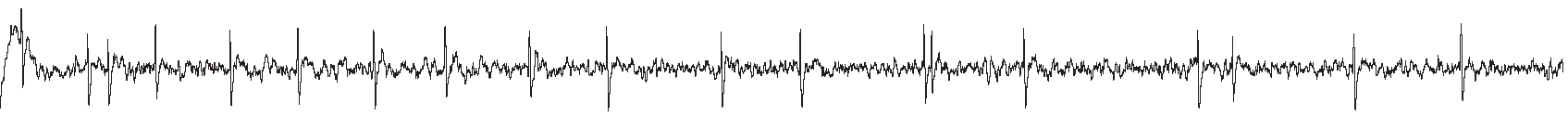

$\mathrm{S}_{+}$GSL extract; $1 \mathrm{gle} / \mathrm{ml} \mathrm{KCl} \mathrm{mM} ; \mathrm{C}_{5}$ sensillum

J.m.

Fig. 4 Electrophysiological recordings from a $\mathrm{C}_{5}$ sensillum stimulated with GSL fractions of $\mathrm{S}_{0}, \mathrm{~S}_{\mathrm{n}}$ and $\mathrm{S}_{+}$B. napus plant extracts. Standard: glucobrassicin (GBR) $10^{-5} \mathrm{M}$, solvent: $\mathrm{KCl} 10 \mathrm{mM}$. gle $/ \mathrm{ml}=$ gram leaf equivalent per $\mathrm{ml} . \mathrm{S}_{0} \stackrel{\mathrm{n}}{=}$ sulphur free, $\mathrm{S}_{\mathrm{n}}=$ normal sulphur and $\mathrm{S}_{+}=$sulphur-rich plant extracts

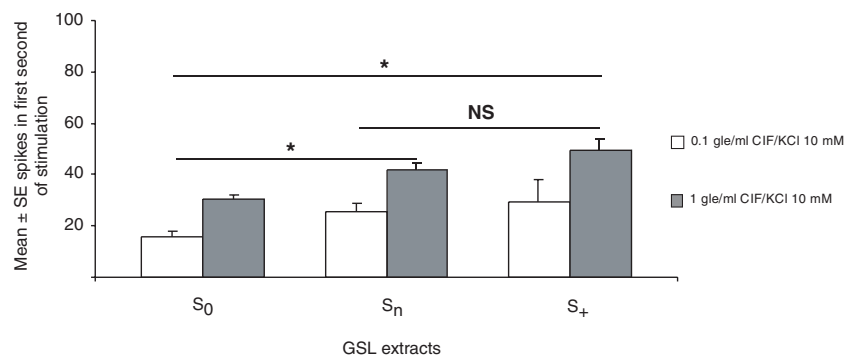

Fig. $5 \mathrm{C}_{5}$ tarsal sensilla neurons of $D$. radicum stimulated by GSL fractions of different $B$. napus varying in $\mathrm{S}$ nutrition. Numbers of analysed recordings: $S_{0}-S_{n}: 15 ; S_{o}-S_{+}: 19 ; S_{n}-S_{+}: 18$. $\mathrm{S}_{0}=$ sulphur free, $\mathrm{S}_{\mathrm{n}}=$ normal sulphur and $\mathrm{S}_{+} \stackrel{\text { sulphur-rich plant }}{=}$ extracts

\section{Sensory physiology}

In agreement with the behavioural data, the chemosensory responses of $D$. radicum were also significantly stronger for $S_{n}$ and $S_{+}$plants than for $S_{0}$ plants. Our results corroborate the view that for this insect contact chemoreception is a very important parameter for stimulation of oviposition.

The oviposition data correlated well with the CIF content of the three samples of B. napus, estimated by the electrophysiological recordings from $\mathrm{C}_{5}$-sensillum and with the response to the GSL fraction. We found that the spike frequency increased depending on the S-concentration of both extracts $(0.1$ and $1 \mathrm{gle} / \mathrm{ml})$, suggesting that $\mathrm{S}$ fertilised plants contain greater amounts of CIF than $S_{0}$ plants. A possible reason for the absence for a stronger correlation could be that other volatile or non-volatile compounds present in the extracts may affect positively or negatively the oviposition behaviour and that the GSL contribute to the sensory imput as well. Specifically, we cannot exclude that the CIF fraction contains unidentified stimulatory or inhibitory plant compounds. If present, they could be detected by one of the other two neurons (total four) (Isidoro et al. 1994) of the $\mathrm{C}_{5}$-sensillum or of the many other sensilla on the tarsi and 
$\mathrm{KCl} 10 \mathrm{mM}$
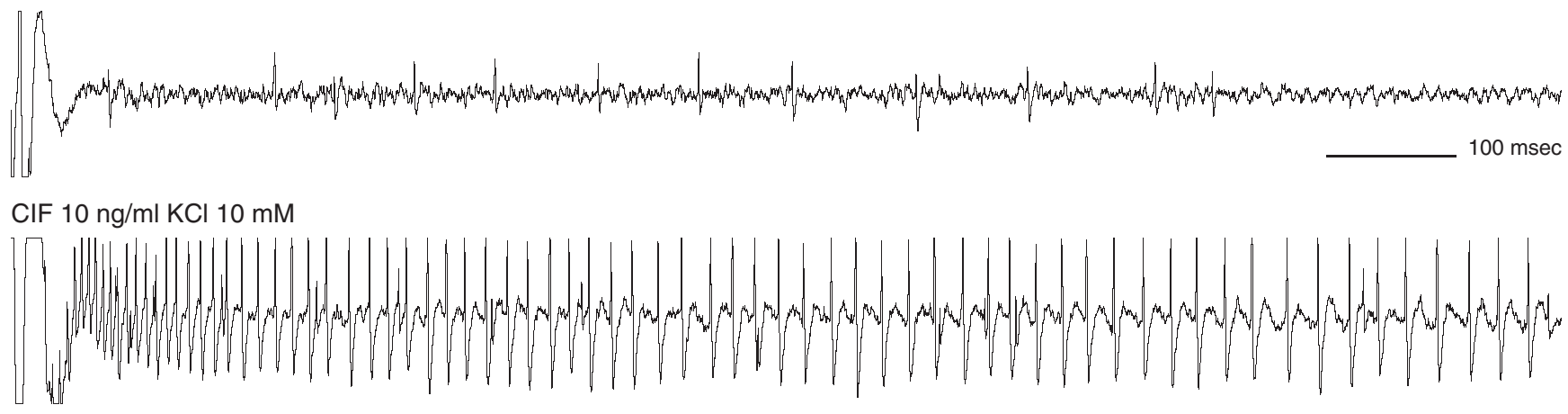

$\mathrm{S}_{\mathrm{o}}$ CIF extract; $1 \mathrm{gle} / \mathrm{ml} \mathrm{KCl} \mathrm{mM}$

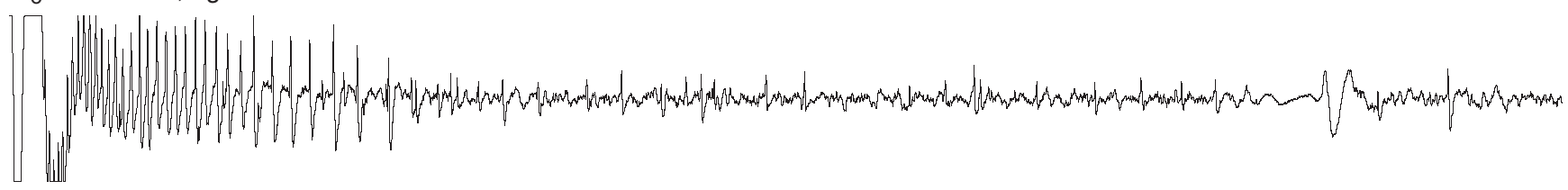

$\mathrm{S}_{\mathrm{n}}$ CIF extract; $1 \mathrm{gle} / \mathrm{ml} \mathrm{KCl} \mathrm{mM}$

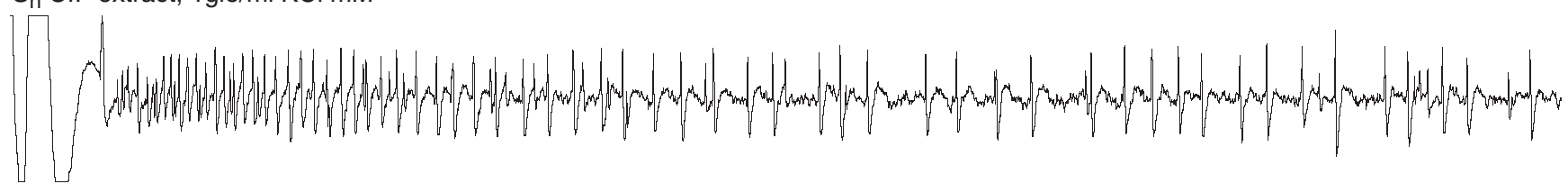

$\mathrm{S}_{+}$CIF extract; $1 \mathrm{gle} / \mathrm{ml} \mathrm{KCl} \mathrm{mM}$

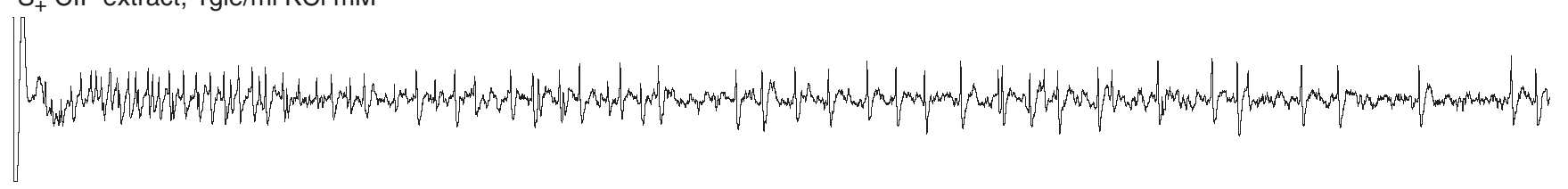

Fig. 6 Electrophysiological recordings from a $\mathrm{C}_{5}$ sensillum stimulated with CIF fractions of $\mathrm{S}_{0}$, $\mathrm{S}_{\mathrm{n}}$ and $\mathrm{S}_{+}$B. napus plant extracts. Standard: CIF $10 \mathrm{ng} / \mathrm{ml} \mathrm{KCl} \mathrm{mM}$, solvent: $\mathrm{KCl} 10 \mathrm{mM}$. gle $/ \mathrm{ml}=$ gram leaf equivalent per ml. $\mathrm{S}_{0}=$ sulphur free, $\mathrm{S}_{\mathrm{n}}=$ normal sulphur and $\mathrm{S}_{+}=$sulphur-rich plant extracts

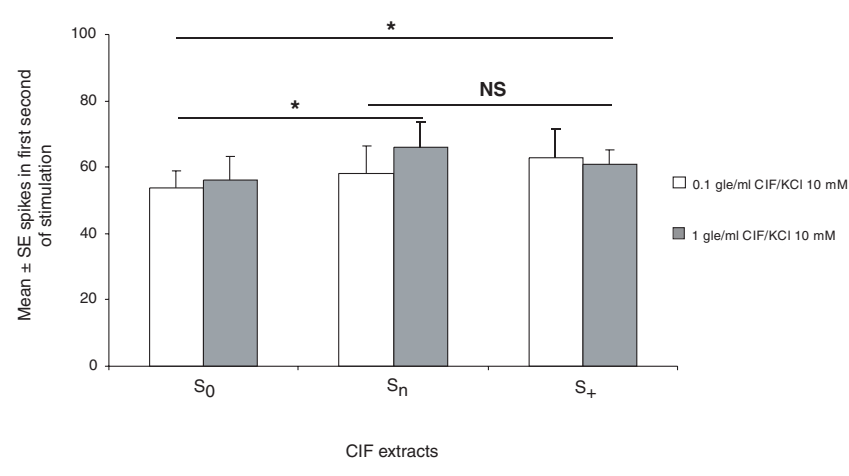

Fig. $7 \quad \mathrm{C}_{5}$ tarsal sensilla neurons of $D$. radicum stimulated by $\mathrm{CIF}$ fractions of different $B$. napus varying in $\mathrm{S}$ nutrition. Numbers of analysed recordings: $\mathrm{S}_{0}-\mathrm{S}_{\mathrm{n}}: 15 ; \mathrm{S}_{0}-\mathrm{S}_{+}: 17 ; \mathrm{S}_{\mathrm{n}}-\mathrm{S}_{+}: 11 . \mathrm{S}_{0}=$ sulphur free, $S_{n}=$ normal sulphur and $S_{+}=$sulphur-rich plant extracts

proboscis and lead to an increase or reduction in spike frequency of the stimulated sensilla. Further, interacting effects that synergise or inhibit the GSL or CIF receptor neurons might be active, as reviewed recently by Chapman (2003).
In conclusion, the observed order of effectiveness in the behavioural and the electrophysiological studies correlate quite well. The two preferred host plants or surrogate leaves $\left(\mathrm{S}_{\mathrm{n}}\right.$ and $\left.\mathrm{S}_{+}\right)$in the oviposition choice contain greater amount of both GSLs and CIF, suggesting, as already pointed out by Städler et al. (2002), that multiple chemical stimuli are important in host acceptance.

Furthermore, the fact that no significant differences in insect behaviour were observed between $S_{n}$ and $S_{+}$plants implies that applying $S$ amounts close to the optimal fertilisation level for oilseed rape will not cause an increase in oviposition, and this is in agreement with the conclusion of Dosdall et al. (2002).

\section{Acknowledgments}

Thanks are due to Ms. Astrid Bächli for valuable help with the chemical analyses and Mrs. Jean Berüter-Cassels for linguistic corrections. We extend our thanks to Dr A. Barker for reviewing an earlier version of this manuscript. This research was included in the COST ACTION NR 829 and supported by the Federal Office for Education and Sciences (project number C 98.0096). 


\section{References}

Baur R, Birch ANE, Hopkins RJ, Griffiths DW, Simmonds MSJ, Städler E (1996) Oviposition and chemosensory stimulation of the root flies Delia radicum and $D$. floralis in response to plant and leaf surface extracts from resistant and susceptible Brassica genotypes. Entomol Exp Appl 78: 61-75

Beaumont G, Bastin R, Therrien HP (1976) Physiological effects of sublethal doses of atrazine on Lemma minor. I. Influence on growth and on the chlorophyll, protein, and total and soluble nitrogen contents. Nat Can 103: 527-533

Bodnaryk RP (1997) Will low-glucosinolate cultivars of the mustards Brassica juncea and Sinapsis alba be vulnerable to insect pests? Can J Plant Sci 77: 283-287

Chapman RF (2003) Contact chemoreception in feeding by phytophagous insects. Annu Rev Entomol 48: 455-484

De Jong R, Städler E (1999) The influence of odour on the oviposition behaviour of the cabbage root fly. Chemoecol 9: 151-154

De Jong R, Maher N, Patrian B, Städler E, Winkler T (2000) Rutabaga roots, a rich source of oviposition stimulants for the cabbage root fly. Chemoecol 9: 205-209

Dosdall LM, Yang R-C, Conway PM (2002) Do applications of sulfur or sulfate influence infestations of root maggots (Delia spp.) (Diptera: Anthomyiidae) in canola? Can J Plant Sci 82: 599-610

Ellis PR, Cole RA, Crisp P, Hardman JA (1980) The relationship between cabbage root fly egg laying and volatile hydrolysis products of radish. Ann Appl Biol 95: 283-289

Finch S, Coaker TH (1969) A method for the continuous rearing of the cabbage root fly Erioischia brassicae (Bch.) and some observations on its biology. Bull Entomol Res 58: 619-627

Griffiths DW, Deighton N, Birch ANE, Patrian B, Baur R, Städler E (2001) Identification of glucosinolates on the leaf surface of plants from the Cruciferae and other closely related species. Phytochemistry 57: 693-700

Hopkins RJ, Ekbom B, Henkow L (1998) Glucosinolate content and susceptibility for insect attack of three populations of Sinapsis alba. J Chem Ecol 24: 1203-1216

Hurter J, Ramp T, Patrian B, Städler E, Roessingh P, Baur R, De Jong R, Nielsen JK, Winkler T, Richter WJ, Müller D, Ernst B (1999) Oviposition stimulants for the cabbage root fly: isolation from cabbage leaves. Phytochemistry 51: 377-382

Isidoro N, Solinas N, Baur R, Roessingh P, Städler E (1994) Functional morphology of a tarsal sensillum of Delia radicum L. (Diptera: Anthomyiidae) sensitive to important host-plant compounds. International Journal of Insect Morphology and Embryology 23: 115-125

Jansson RK, Leibee GL, Sanchez CA, Lecrone SH (1991) Effects of nitrogen and foliar biomass on population parameters of cabbage insects. Entomol Exp Appl 61: 7-16

Kim SJ, Matsuo T, Watanabe M, Watanabe Y (2002) Effect of nitrogen and sulphur application on the glucosinolate content in vegetable turnip rape (Brassica rapa L.). Soil Sci Plant Nutr 48: 43-49

Koritsas VM, Garsed SG (1985) The effect of nitrogen and sulphur nutrition on the response of Brussels sprout plants to infestation by the aphid Brevicoryne brassicae. Ann Appl Biol 106: $1-15$

Received 12 September 2003; accepted 18 November 2003.
Nair KSS, McEwen FL (1976) Host selection by the adult cabbage maggot, Hylemya brassicae (Diptera, Anthomyiidae). Can Entomol 108: 1021-1030

Nottingham SF, Coaker TH (1985) The olfactory response of cabbage root fly, Delia radicum, to the host plant volatile allylisothiocyanate. Entomol Exp Appl 39: 307-316

Prokopy RJ, Roitberg BD (2001) Joining and avoidance behaviour in nonsocial insects. Annu Rev Entomol 46: 631-665

Roessingh P, Städler E (1990) Foliar form, colour and surface characteristics influence oviposition behaviour of the cabbage root fly Delia radicum. Entomol Exp Appl 57: 93-100

Roessingh P, Städler E, Fenwick GR, Lewis JA, Nielson JK, Hurter J, Ramp T (1992a) Oviposition and tarsal chemoreceptors of the cabbage root fly are stimulated by glucosinolates and host plant extracts. Entomol Exp Appl 65: 267-282

Roessingh P, Städler E, Hurter J, Ramp T (1992b) Oviposition stimulant for the cabbage root fly: important new cabbage leaf surface compound and specific tarsal receptor. Pp 141-142 in Menken SBJ, Visser JH, Harrewijn P (eds) 8th International Symposium on Insect-Plant Relationships. NL-Dordrecht: Kluwer Academic Publishers

Roessingh P, Städler E, Baur R, Hurter J, Ramp T (1997) Tarsal chemoreceptors and oviposition behaviour of the cabbage root fly (Delia radicum) sensitive to fractions and new compounds of host leaf surface extracts. Physiol Entomol 22: 140-148

Scherer HW (2001) Sulphur in crop production - invited paper. Eur J Agron 14: 81-11

Städler E, Roessingh P (1991) Perception of surface chemicals by feeding and ovipositing insects. Pp 71-86 in Szentesi Á (ed), 7th International Symposium on Insect-Plant Relationships Vol. 39, HU-Budapest: Symposia Biologica Hungarica

Städler E (2002) Plant chemical cues important for egg deposition by herbivorous insects. Pp 171-197 in Hilker M, Meiners T (eds) Chemoecology of insect eggs and egg deposition. GB-Oxford: Blackwell

Städler E, Baur R, De Jong R (2002) Sensory basis of host-plant selection: in search of the "fingerprints" related to oviposition of the cabbage root fly. Acta Zool Acad Sci Hung 48: 265-280

Tuttle AF, Ferro DN, Idoine K (1988) Role of visual and olfactory stimuli in host finding of adult cabbage root flies, Delia radicum. Entomol Exp Appl 47: 37-44

Wallbank BE, Wheatley GA (1979) Some responses of cabbage root fly (Delia brassicae) to allyl isothiocyanate and other volatile constituents of crucifers. Ann Appl Biol 91: $1-12$

Wolfson JL (1980) Oviposition response of Pieris rapae to environmentally induced variation in Brassica nigra. Entomol Exp Appl 27: 223-232

Wolfson JL (1982) Developmental responses of Pieris rapae and Spodoptera eridania to environmentally induced variation in Brassica nigra. Environ Entomol 11: 207-213

Yusuf SW, Collins GC (1998) Effect of soil sulphur levels on feeding preference of Brevicoryne brassicae on brussels sprouts. J Chem Ecol 1998: 417-424

To access this journal online:

http://www.birkhauser.ch 